\title{
HARD TURNING ASSESSMENT ON EN31 STEEL IN DRY AND WET COOLING ENVIRONMENTS USING GREY-FUZZY HYBRID OPTIMIZATION APPROACH
}

\author{
Saswat Khatai, Ramanuj Kumar, Ashok Kumar Sahoo \\ School of Mechanical Engineering, KIIT Deemed to be University \\ Bhubaneswar-751024, Odisha, India \\ Corresponding author: Ramanuj Kumar, ramanujfme@kiit.ac.in
}

\begin{abstract}
In recent years, machining of hard-to-cut metals by hard turning process is an embryonic technology for machining industry and research development. Hard turning is generally defined as the material removal process of hardened steel having hardness greater than 45 HRC. The current research presents a comparative hard turning investigation on EN $31(56 \pm 1 \mathrm{HRC})$ grade steel using physical vapor deposition (PVD) coated carbide tool under dry and wet cooling. The selection of a better cooling strategy among dry and wet cooling was based on the value of obtained surface roughness $\left(R_{a}\right)$ and material removal rate (MRR) in hard turning. Wet cooling exhibited better performance over dry cutting as lower $\mathrm{R}_{\mathrm{a}}$ and greater MRR are achieved with wet cooling. Further, considering Taguchi $\mathrm{L}_{16}$ orthogonal array, hard turning experiments were executed in wet cooling and responses like surface roughness $\left(R_{a}\right)$, material removal rate $(M R R)$, and diameter error were studied. Further, the Grey-fuzzy hybrid optimization tool was employed and found improved results relative to the alone grey relational analysis as about $9 \%$ less $\mathrm{R}_{\mathrm{a}}$ and 2.612 times more MRR is noticed at the grey fuzzy optimal set of parameters.
\end{abstract}

Key words: hard turning, PVD, wet cooling, surface roughness, material removal rate, grey-fuzzy hybrid optimization.

\section{INTRODUCTION}

Hard turning plays a decisive role in improving the manufacturing productivity of the enterprises due to some key benefits resulting in successful implantation. Hard turning is a machining process of hardened steel bars having hardness above 45 HRC (Kumar et al., 2018). It is very challenging in the selection of tool inserts with improved tool life and high-precision machining. Hard turning of steels by using the single-point cutting tool is very popular among manufacturers of ball bearings, automotive, gear, and die industry. Hard turning replaced the use of grinding process for manufacturing of various automotive and bearing components due to its lesser operating cost, shorter set-up time, a higher degree of flexibility, and ability to machine complex geometries (Shihab et al., 2014).

Cutting tools play a major role during the machining process and also the cost of the cutting tool contrived the overall manufacture value. The cutting ability of the tool depends on the different factors like tool geometry, tool materials, power of the workpiece, appealed cooling/lubrication conditions, input cutting parameters, etc. A hard film or layer applied on the cutting insert enhanced the performance of the tools as the coated layer made a blockade between the workpiece and the tool substrate materials. Using coated tools shows better results than uncoated tools which may reduce the surface roughness and tool wear. TiAlN-based hard coatings deposited by physical vapor deposition (PVD) provide low surface roughness and high wear resistance (Vogli et al., 2011). Due to high oxidation resistance, these tools can be used in elevated temperatures applications (Tillmann et al., 2013). During the turning of the hard materials, a large amount of heat is generated at the cutting point which affects the machining performance and it can be controlled by the use of suitable coolant/lubricant with its appropriate delivery techniques.

Mia et al., 2018 found the existence of extreme temperature in hardened steel dry turning. However, it was recommended to implement coolant/lubricant during cutting to reduce the thermal effect on the machining performances. Minimum quantity lubrication (MQL) performed better as compared to the dry, wet, and spray condition respectively in terms of better tool life, surface quality, and green manufacturing. (Vishnu et al., 2017) experimented on turning of EN 353 steel under dry, wet, and MQL conditions and found better results with wet conditions relative to dry and MQL conditions. According to (Mukherjee et al., 2014), cutting depth was the leading term for MRR in CNC turning on SAE 1020 steel by carbide cutting tool. (Mia et al., 
2018), concluded that the speed was the topmost turning term to influence $R_{a}$, while feed afflicted the MRR largely. (Power and Raval, 2016) stated that feed is the most influenced factor for Surface Roughness with a contribution of $63.12 \%$ while hard turning of EN 24 steel under MQL condition.

Further, several traditional optimization tools were implemented in the hard turning process. (Kumar et al., 2018) examined the impact of the multilayercoated cutting tool at the time of hard turning and from the optimization found the optimal cutting condition for the roughness of the machined workpiece surface by applying the grey relation approach. (Kumar et al., 2021) also utilized the Greyfuzzy approach to select optimal parameters in the hard turning process. In another work, (Pandey et al., 2019) utilized TOPSIS optimization for the hard turning. (Nikam et al., 2021) utilized the GRA technique to optimize cutting force magnitude and surface roughness in the machining of AISI 4140 steel. (Senthilkumar et al., 2015) have utilized hybrid grey-fuzzy algorithm, in turning of AISI 1045 steel. According to (Venkataramaiah et al., 2015), fuzzy logic reduces the fuzziness in the output to provide enhanced optimal settings.

In current years, the coated carbide tools have a tremendous contribution to the machining enterprise in phrases of a variety of machining performances. However, not many authors specifically concentrated on the comparative study of different cutting conditions using EN31 bearing steel and PVD coated tools. There are rarely works reported the use of EN 31 steel under wet cooling environment. Therefore, for the practical machining conditions, to minimize the unforeseen risks of the operator and enhance the production rate, a very conservative optimal combination of cutting parameters is required for the benefits of machining industries. Therefore, the modern work proposed the use of the most applicable grey-fuzzy hybrid optimization tool to predict the optimum set of input parameters.

\section{MATERIAL AND METHOD}

In this work, a cylindrical workpiece of EN-31 steel (56 $\pm 1 \mathrm{HRC}$ ) having a diameter of $50 \mathrm{~mm}$ and a length of $200 \mathrm{~mm}$ was selected for the experimentation. EN-31 offers high corrosion resistance and high strength and toughness even at elevated temperatures and is mostly used in the production of ball bearing, spindle and axle, punches, and dies. The cutting length was considered as $150 \mathrm{~mm}$. WIDIA manufactured PVD multi-layer coated carbide insert (CNMG120408UR-WS10PT grade) was utilized in the present experiment. Finish hard turning experiments were carried out with the help of ACE manufactured CNC Turning Centre (Model: LT 16 LM) having spindle speed range $50 \mathrm{rpm}$ to $4000 \mathrm{rpm}$.
Initially, at different cutting parameters settings, the finish turning performances in dry and wet cooling were compared. Blasocut 4000 strong-cutting fluid was utilized as a wet cooling coolant. It is a water-miscible mineral oil-based high-performance cutting fluid. It is suitable for heavy-duty machining of cast iron, steel, and aluminum alloys. The ratio of lubricant and water is taken as 1:20. The mixed coolant is impinging at the cutting point with a flow rate of $300 \mathrm{l} / \mathrm{hr}$. Wet cooling exhibited better performance over dry turning hence further $\mathrm{L}_{16}$ design of experiments were chosen to detail study of hard turning performances in wet cooling. Three basic turning input parameters like cutting depth, axial feed, and cutting speed were selected for the experimentations and their values are listed in Table 1. The performance indexes namely surface roughness, diameter error, and material removal rate have been investigated in detail. The experimental setups for dry and wet cooling are displayed in Figure 1. Digimatic caliper a product of Mitutoyo Corporation is used to measure the diameter of the workpiece. A surface roughness tester of model SJ-416 (manufactured by Mitutoyo Corporation) was used for the test of the surface roughness $\left(R_{a}\right)$ of the finished workpiece material after the completion of every run. For the calculation of material removal rate (MRR) during the machining process, an electronic weight device was used to measure the workpiece weight before and after machining. To get the MRR in grams per min, the absolute difference of weight was divided by machining time. MINITAB 17 tool was utilized for ANOVA, main effect plot, and surface plot analysis. Further, MATLAB (R2013a) is used for Grey-fuzzy hybrid optimization of the cutting factors.

Table 1. Details of input parameters

\begin{tabular}{|l|c|c|c|c|}
\hline Parameters & Level 1 & Level 2 & Level 3 & Level 4 \\
\hline $\begin{array}{l}\text { Depth of cut (t), } \\
\text { mm }\end{array}$ & 0.15 & 0.25 & 0.35 & 0.45 \\
\hline $\begin{array}{l}\text { Feed (s), } \\
\text { mm/rev }\end{array}$ & 0.06 & 0.12 & 0.18 & 0.24 \\
\hline $\begin{array}{l}\text { Cutting speed } \\
\text { (v), m/min }\end{array}$ & 60 & 120 & 180 & 240 \\
\hline
\end{tabular}

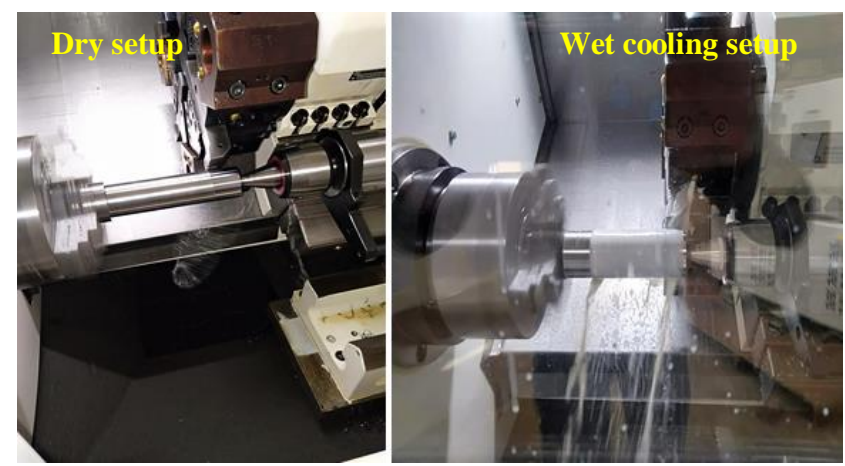

Fig. 1. Experimental setup for dry and wet cooling hard turning 


\section{COMPARATIVE CUTTING PERFORMANCE ASSESMENT IN DRY AND WET COOLING ENVIRONMENT}

To select the better environment between dry and wet cooling, pilot experiments were conducted. In these pilot experiments, four different runs are conducted under both dry and wet cooling environments. The comparative study was based on results of surface roughness (Figure 2) and MRR (Figure 3) obtained under both cooling conditions. From these experiment results, the hard turning performance under wet cooling conditions is noticed to be superior to dry conditions. Lower combinations of cutting parameters (Trial No. 1) exhibited the least $R_{a}$ and MRR while the largest combinations of cutting parameters (Trial No. 4) produced the largest $R_{a}$ and MRR. At the constant depth of cut $(0.15 \mathrm{~mm}), \mathrm{R}_{\mathrm{a}}$ and MRR are increasing with feed and speed value. On average, surface roughness under wet cooling is found to be $16 \%$ lesser than dry conditions, while MRR is $11 \%$ more than dry conditions. However, based on these trial experiments study, it can be stated that the cutting ability under wet coolant is better than dry cutting hence further study will be performed under wet cooling only.

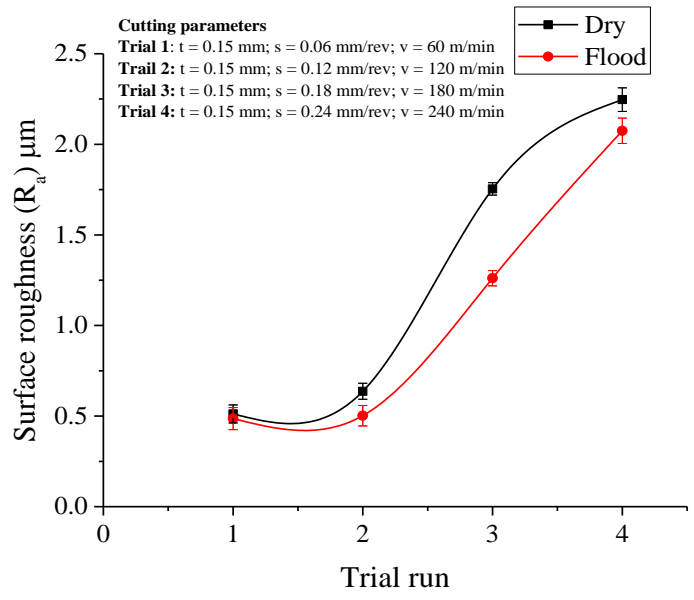

Fig. 2. Comparison of $R_{a}$ under dry and wet cooling

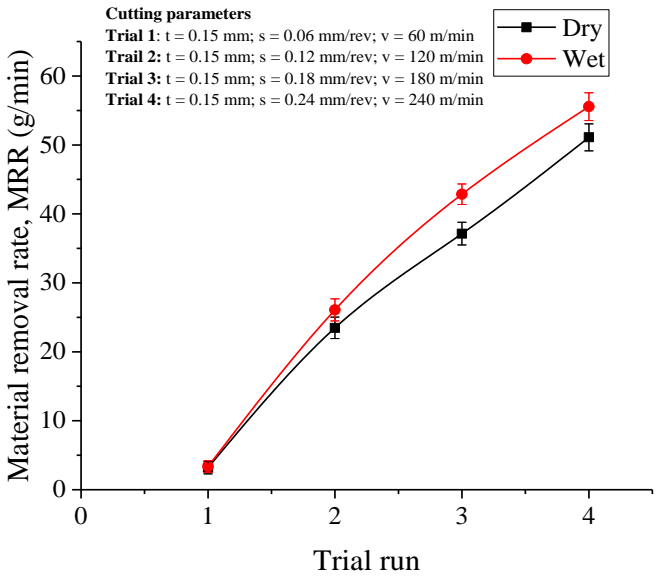

Fig. 3. Comparison of MRR under dry and wet cooling

\section{CUTTING PERFORMANCE EVALUATION UNDER WET COOLING ENVIRONMENT}

The actual $\mathrm{L}_{16}$ input terms along with measured responses namely average surface roughness $\left(R_{a}\right)$ and material removal rate (MRR) for current hard turning work under wet cooling circumstances are displayed in Table 2.

Table 2. Turning test results

\begin{tabular}{|c|c|c|c|c|c|}
\hline $\begin{array}{l}\text { Test } \\
\text { No. }\end{array}$ & \multicolumn{3}{|c|}{$\begin{array}{c}\text { Input terms setting for } \mathrm{L}_{16} \\
\text { design }\end{array}$} & \multicolumn{2}{|c|}{ Responses } \\
\hline & $\begin{array}{c}\mathrm{t} \\
(\mathrm{mm})\end{array}$ & $\begin{array}{c}\mathrm{s} \\
(\mathrm{mm} / \mathrm{rev})\end{array}$ & $\begin{array}{c}\mathrm{v} \\
(\mathrm{m} / \mathrm{min})\end{array}$ & $\begin{array}{c}\mathrm{R}_{\mathrm{a}} \\
(\mu \mathrm{m})\end{array}$ & $\begin{array}{c}\text { MRR } \\
(\mathrm{g} / \mathrm{min})\end{array}$ \\
\hline 1 & 0.15 & 0.06 & 60 & 0.486 & 3.3613 \\
\hline 2 & 0.15 & 0.12 & 120 & 0.502 & 26.0870 \\
\hline 3 & 0.15 & 0.18 & 180 & 1.261 & 42.8571 \\
\hline 4 & 0.15 & 0.24 & 240 & 2.075 & 55.5556 \\
\hline 5 & 0.25 & 0.06 & 120 & 0.665 & 10.2439 \\
\hline 6 & 0.25 & 0.12 & 60 & 0.868 & 18.4158 \\
\hline 7 & 0.25 & 0.18 & 240 & 1.192 & 48.0000 \\
\hline 8 & 0.25 & 0.24 & 180 & 2.312 & 48.3333 \\
\hline 9 & 0.35 & 0.06 & 180 & 0.65 & 34.0909 \\
\hline 10 & 0.35 & 0.12 & 240 & 0.728 & 57.6923 \\
\hline 11 & 0.35 & 0.18 & 60 & 1.437 & 30.2326 \\
\hline 12 & 0.35 & 0.24 & 120 & 2.218 & 44.7059 \\
\hline 13 & 0.45 & 0.06 & 240 & 0.539 & 65.6250 \\
\hline 14 & 0.45 & 0.12 & 180 & 0.623 & 71.0769 \\
\hline 15 & 0.45 & 0.18 & 120 & 1.224 & 61.3636 \\
\hline 16 & 0.45 & 0.24 & 60 & 2.125 & 51.7021 \\
\hline
\end{tabular}

\subsection{Evaluation of surface roughness}

In this competitive scenario, good quality of the machined surface is a prime need, and also, it is a challenging task for the metal machining industries. Surface quality for hard-turned material is studied considering $1.6 \mu \mathrm{m}$ criteria which are globally acceptable (Kumar et al., 2018). Overall, the $\mathrm{R}_{\mathrm{a}}$ lies in between 0.486 to $2.312 \mu \mathrm{m}$. Magnitudes of $R_{a}$ exceed $1.6 \mu \mathrm{m}$ when machining feed is kept at the largest level $(0.24 \mathrm{~mm} / \mathrm{rev})$. Theoretically, from open literature, it was proved that the $\mathrm{R}_{\mathrm{a}}$ was largely influenced by tool feed. In other test runs, $R_{a}$ lies within $1.6 \mu \mathrm{m}$ which shows the effectiveness of the wet cooling strategy even at larger feed (up to $0.18 \mathrm{~mm} / \mathrm{rev}$ ) and larger speed (up to $240 \mathrm{~m} / \mathrm{min}$ ) conditions. The current finding definitely attracts the machinist to use PVD-coated tools in turning hard metals at the highest turning parameters. 
Further, the graphs (Figure 4) indicate that the $R_{a}$ was leading gradually when the feed increased from 0.06 to $0.24 \mathrm{~mm} / \mathrm{rev}$ but the rate of increment in $R_{a}$ was more severe when the feed exceed $0.12 \mathrm{~mm} / \mathrm{rev}$. The impact of the depth of cut towards $R_{a}$ was not much noteworthy as very few changes are noticed in $R_{a}$ when it increases from 0.15 to $0.25 \mathrm{~mm}$ and 0.35 to $0.45 \mathrm{~mm}$. Effects on $R_{a}$ due to change in speed are insignificant as graphs proceed along the mean line.

From surface plots (Figure 5(a-b)), the combined effects of depth of cut-feed and cutting speed-feed on $\mathrm{R}_{\mathrm{a}}$ were relevant while the combined influence of speed-depth of cut (Figure 5(c)) was not relevant as surface slope variation is random. The surface plot confirms the same trend $\left(R_{a}\right.$ increases with feed) which was obtained through the main effect plot (Figure 4). The surface plot (Figure 5(a-b)) clearly showed that the pair of the larger depth of cut-larger feed condition attributed to the larger values of surface roughness. Further, the impact of input terms on $R_{a}$ was quantitatively analyzed with the ANOVA tool (Table 3). The largest contribution on $R_{a}$ was associated with feed $(97.53 \%)$ while the impact of depth of cut and speed was very less. Considering $95 \%$ of confidence level (i.e. $p \leq 0.05$ ), the terms feed and depth of cut are noticed to be significant while speed is insignificant. However, based on these discussions feed is the topmost responsible term that severely affects the $\mathrm{R}_{\mathrm{a}}$ or quality of finish.

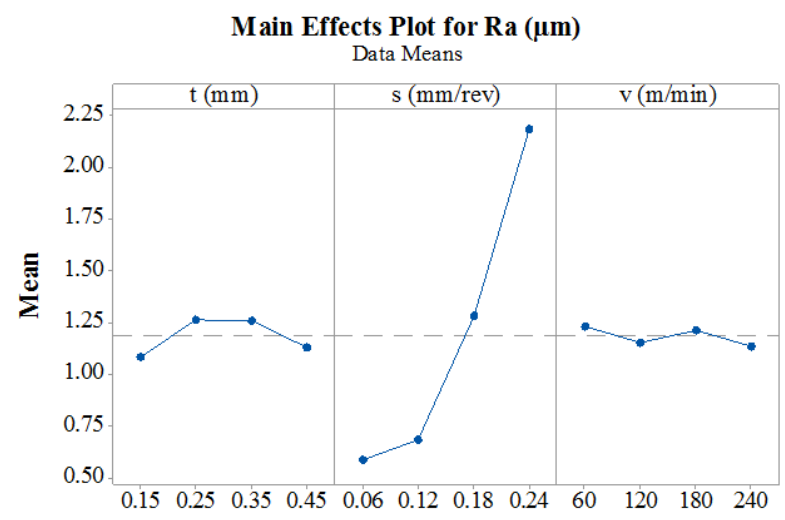

Fig. 4. Influence of input terms on $\mathrm{R}_{\mathrm{a}}$ in wet cooling

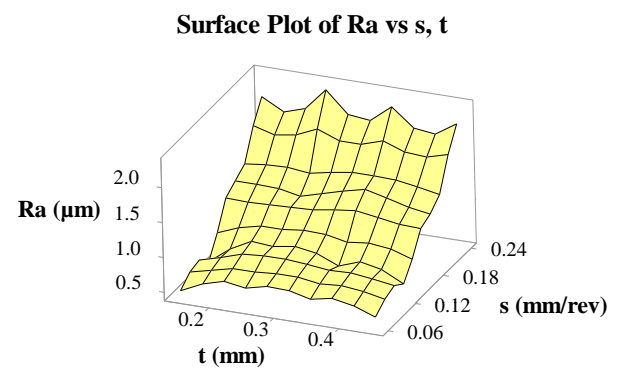

(a)

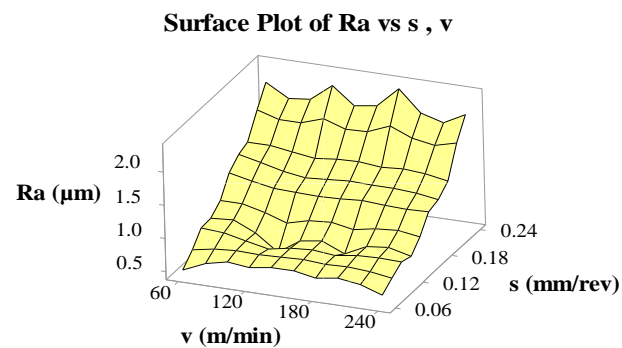

(b)

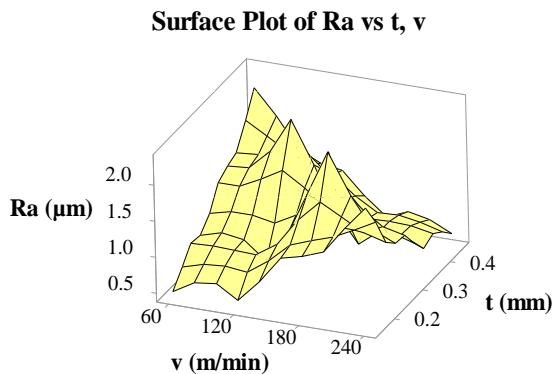

(c)

Fig. 5. 3-dimensional surface plot of $R_{a}$ in wet cooling

Table 3. ANOVA report of $R_{a}$

\begin{tabular}{|c|c|c|c|c|c|c|}
\hline $\begin{array}{l}\text { Term } \\
\mathrm{s} \\
\end{array}$ & $\begin{array}{l}\mathrm{D} \\
\mathrm{F}\end{array}$ & Adj SS & Adj MS & $\mathrm{F}$ & $\mathrm{P}$ & $\begin{array}{l}\% \\
\text { Share }\end{array}$ \\
\hline $\mathrm{t}$ & 3 & 0.09970 & 0.03323 & 5.12 & 0.043 & 1.50 \\
\hline $\mathrm{s}$ & 3 & 6.47390 & 2.15797 & 332.56 & 0.000 & 97.53 \\
\hline $\mathrm{v}$ & 3 & 0.02526 & 0.00842 & 1.30 & 0.358 & 0.38 \\
\hline Error & 6 & 0.03893 & 0.00649 & & & \\
\hline Total & 15 & 6.63779 & & & & \\
\hline \multicolumn{3}{|c|}{$\begin{array}{l}\text { R-Square }=99.41 \% \\
\text { Square }(\text { pred })=95.83 \%\end{array}$} & & adj) & 98 & $\mathrm{R}-$ \\
\hline
\end{tabular}

\subsection{Evaluation of material removal rate}

The material removal rate is an important scientific measure to analyze the productivity of any metal removal process. Productivity directly influences the total expenditure of machining for an individual machined part. However, considering this view, the current work estimated the MRR in $\mathrm{g} / \mathrm{min}$. Here, MRR is the ratio of the weight of material removed (Initial weight of job - weight of job after machining) and cutting time. The results for MRR are listed in Table 2. The range of MRR is noticed to be 3.3613 to $71.0769 \mathrm{~g} / \mathrm{min}$. Lowest MRR was found when the first level of all input terms is utilized for machining. Higher ranges of MRR are achieved when the depth of cut is largest $0.5 \mathrm{~mm}$. Also, combinations of larger feed and speed exhibited moderate to larger MRR. Further, from the main effects graphs (Figure 6), MRR is growing when the depth of cut increases from 0.25 to $0.45 \mathrm{~mm}$ while at smaller values $(0.15$ 
and $0.25 \mathrm{~mm}$ of the depth of cut, MRR is reducing slightly. MRR is almost linearly increased when speed increases from 60 to $240 \mathrm{~m} / \mathrm{min}$.

Further, from the surface plot (Figure 7(a)), MRR is rising when pairing of terms feed-depth of cut are improving while MRR is also improved when increases with feed (Figure 7(b)) speed. Also, an increase in MRR due to leading values of speed and depth of cut is noticed in Figure 7(c). ANOVA (Table 4) numerically listed the contribution of each input term on MRR. Depth of cut is the topmost influencing term which largely influences the MRR with a contribution of $43 \%$ succeeded by speed $(38.38 \%)$ and feed $18.09 \%$. (Madival et al., 2019) also found similar results. All input terms are traced to be significant at $95 \%(\mathrm{p} \leq 0.05)$ confidence. However, larger values of all three input terms are recommended to get the larger MRR.

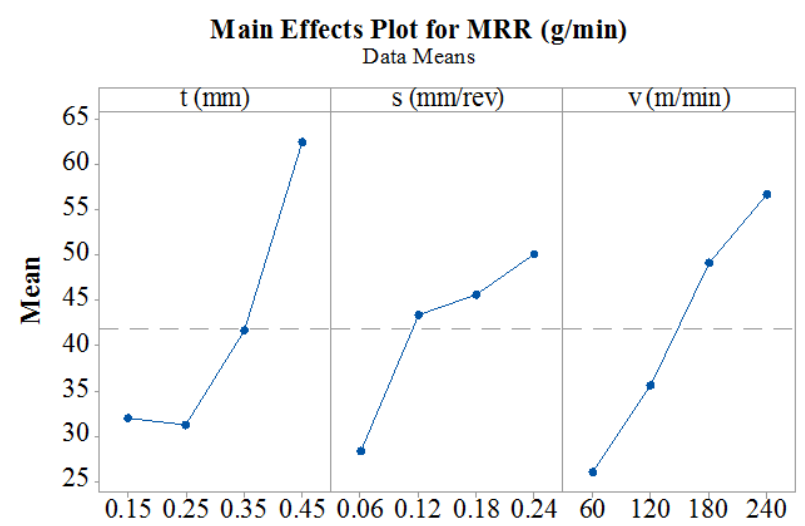

Fig. 6. Influence of input terms on MRR

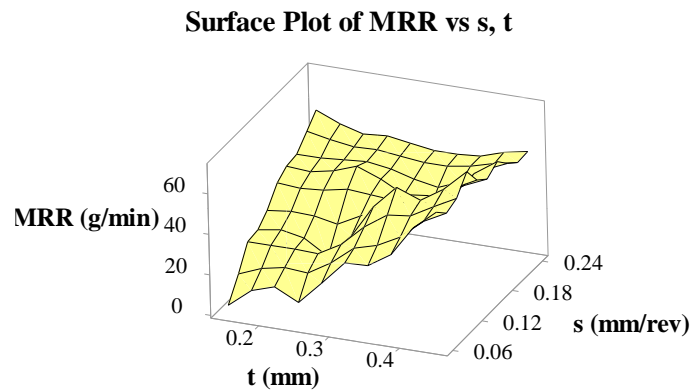

(a)

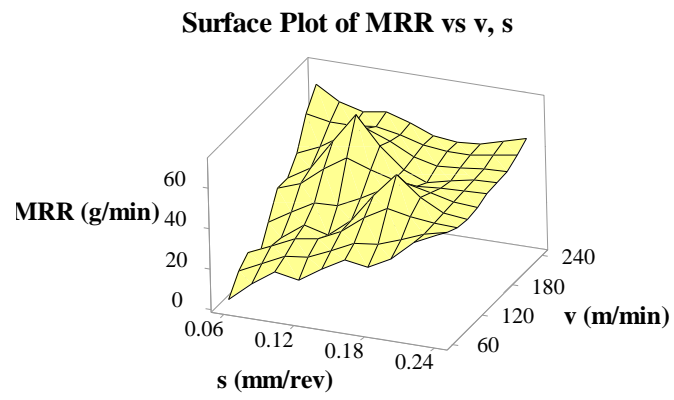

(b)

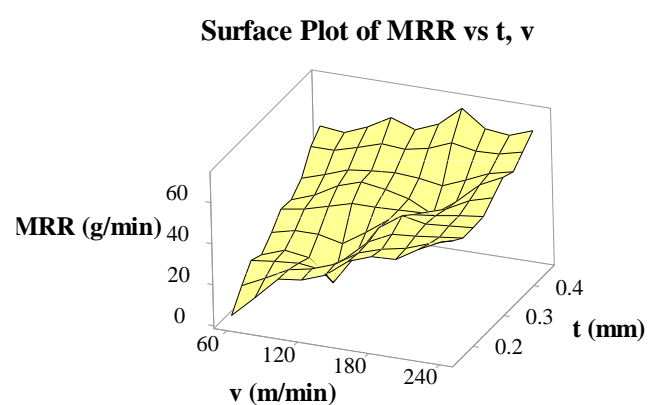

(c)

Fig. 7. 3 dimensional surface plots for MRR

Table 4. ANOVA report for MRR

\begin{tabular}{|c|c|c|c|c|c|c|}
\hline Terms & DF & Adj SS & Adj MS & F & P & $\begin{array}{c}\% \\
\text { Share }\end{array}$ \\
\hline $\mathrm{t}$ & 3 & 2536.64 & 845.547 & 166.33 & 0.000 & 43.00 \\
\hline $\mathrm{s}$ & 3 & 1066.95 & 355.650 & 69.96 & 0.000 & 18.09 \\
\hline $\mathrm{v}$ & 3 & 2264.19 & 754.729 & 148.46 & 0.000 & 38.38 \\
\hline Error & 6 & 30.50 & 5.084 & & & \\
\hline Total & 15 & 5898.28 & & & & \\
\hline \multicolumn{7}{|c|}{ R-Square $=99.48 \%$, R-Square $(\mathrm{adj})=98.71 \%$, R-Square(pred) $=$} \\
$96.32 \%$
\end{tabular}

\subsection{Evaluation of machined workpiece diameter error}

The diameter error of the machined workpiece for each run was calculated. After machining, the workpiece diameter is measured in the middle of the length using a digital caliper. According to (Mayer et al., 2000) more diameter error was noticed at the center portion of the workpiece because of the least stiffness of parts near the center portion of the turned piece. Required diameter (initial diameter $-2 \mathrm{t}$ ) is compared with measured diameter and \% error was estimated using the equation (1).

$$
\operatorname{Error}(\%)=\frac{\left(D_{\text {required }}-D_{\text {measured }}\right)}{D_{\text {required }}} \times 100
$$

Where, $D_{\text {required }}$ is the diameter of the workpiece required after machining while $D_{\text {measured }}$ is the measured diameter of the workpiece after machining. The calculated diameter error is graphically shown in Figure 8. The diameter error occurs due to radial force acting along cross feed direction i.e. a force acting on a simply supported beam ( workpiece) so maximum deflection occurs at the center portion of the workpiece which ultimately exhibited the diameter error of turned workpiece which is supported by the head stock and tail stock at each end. In the majority of runs, the negative error is found because of the deflection of the tool due to radial force. While the positive error may occur due to human error as the depth of cut is given 
manually. The maximum diameter error (\%) was traced below $\pm 0.6 \%$ for entire experiments which confirms the stable machining and can be recommended for precision work also.

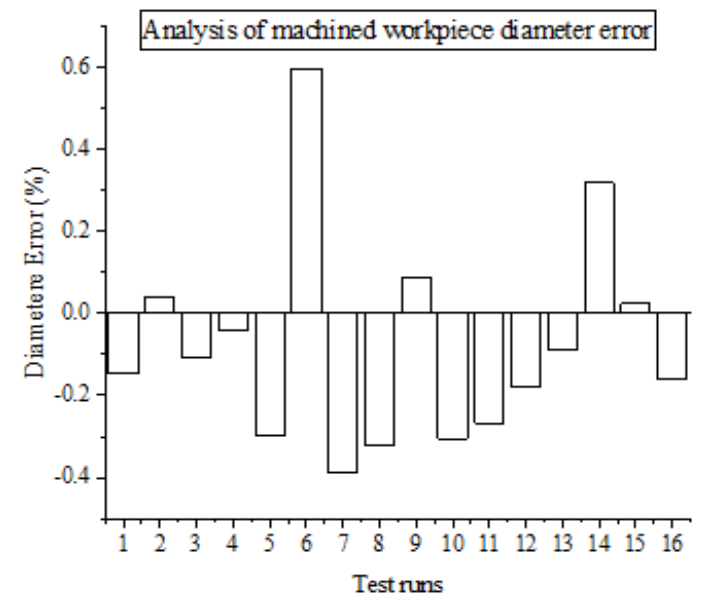

Fig. 8. Diameter error (\%) for each run

\section{GREY-FUZZY HYBRID OPTIMIZATION}

\subsection{Grey relational analysis}

Grey relational analysis (GRA) is the well-known optimization process for hard turning. According to the GRA (Kumar et al., 2018), the real data (obtained from experiments) of each output is early normalized from 0 to 1 using smaller the better principle and this procedure is termed as a grey relational generation. In the next stage, the grey relational coefficient for every output is estimated by the usage of normalized data. Equation (1) and Equation (2) are utilized to evaluate grey relational generation and grey relation coefficient respectively.

$$
H_{x}(e)=\frac{\max j_{x}(e)-j_{x}(e)}{\max j_{x}(e)-\min j_{x}(e)}
$$

Where, $H_{x}(\mathrm{e})$ denotes the grey relational generation value, $\min J_{x}(\mathrm{e})$ is the lowest value of $J_{x}(\mathrm{e})$ for the $\mathrm{e}^{\text {th }}$ output, and $\max J_{x}(\mathrm{e})$ is the highest value of $J_{x}(\mathrm{e})$ for the $\mathrm{e}^{\text {th }}$ output. $H_{0}(\mathrm{e})$ is the reference sequence, where ' $\mathrm{e}$ ' is equal to $1,2,3,4,5, \ldots$. (Numbers of outputs). Further, the grey relational coefficient (GRC) is symbolized as $\lambda_{x}(e)$.

$$
\lambda_{x}(e)=\frac{\Delta_{\min }+\phi \Delta_{\max }}{\Delta_{0 x}(e)+\phi \Delta_{\max }}
$$

Where, $\Delta_{0 x}(\mathrm{e})=H_{0}(\mathrm{e})-H_{x}(\mathrm{e})$ is the absolute difference value between $H_{0}(\mathrm{e})$ and $H_{x}(\mathrm{e}) . \Delta_{\min }$ and $\Delta_{\max }$ denote the smallest and largest values of the absolute variations $\Delta_{0 \mathrm{x}}$ of all evaluating sequences, respectively. $\phi$ refers to a suggestive coefficient (0 to
$1)$, and in the present study, $\phi$ is taken to be (1/2). In the subsequent step, the final grey relational grade is evaluated by using the mean of the grey relational coefficient equivalent to the considered outputs. The high aim is to set up the degree of relation between the sequences $H_{0}(\mathrm{e})$ and $H_{x}(\mathrm{e})$. The GRG is estimated using equation 3 .

$$
\rho_{x}=\frac{1}{n} \sum_{e=1}^{n} \lambda_{x}(e)
$$

where, $\rho_{\mathrm{x}}$ is expressed as grey relational grade and $\mathrm{x}$ $=1,2,3, \ldots ., 16$ (no of each output data), $\mathrm{n}$ is the number of outputs.

\subsection{Fuzzy approach}

Grey theory holds lots of uncertainty although it considers all three basic principles such as smaller the better, nominal the better, and greater the better. This uncertainty can be efficiently curbed through a fuzzy logic concept (Senthilkumar et al., 2019, Venkataramaiah et al., 2015). However, a fuzzy approach for multi-attributes was executed and commonly notorious as grey-fuzzy logic. The optimization process can be executed taking a single response (grey-fuzzy grade) compared to complex multi-outputs.

The fuzzy consists of a fuzzifier, a membership function, rule inference, an inference engine, and a defuzzifier. Initially, the fuzzifier uses the membership function to fuzzify input terms (GRC$\mathrm{R}_{\mathrm{a}}$, and GRC-MRR). Membership function expresses the mapping of inputs (GRC- $\mathrm{R}_{\mathrm{a}}$ and GRC-MRR) and output (Grey fuzzy grade, GFG) in the range of 0 to 1. Matlab (R2013a) fuzzy-toolbox is used to estimate the grey-fuzzy grade. The Gaussian membership function is used in the current process. Further, the membership function for inputs and output is kept as same as five (Very Low, Low, Medium, High, Very high). The membership graph for output is displayed in Figure 9. Further, 11 distinguish rules are considered and it is mentioned in Table 5. Next, the GFG data has been defuzzified using the centroid method. Further, the rules viewer for the highest value of GFG (run 1) is displayed in Figure 10. In rule viewer figure (Figure 10), rows denote the number of membership function rules, $1^{\text {st, }}$ and $2^{\text {nd }}$ column shows input terms (i.e. GRC for the experimentally obtained value of $R_{a}$ and MRR) and $3^{\text {rd }}$ column indicates output response i.e. defuzzified data is called as GFG (grey fuzzy grade). 


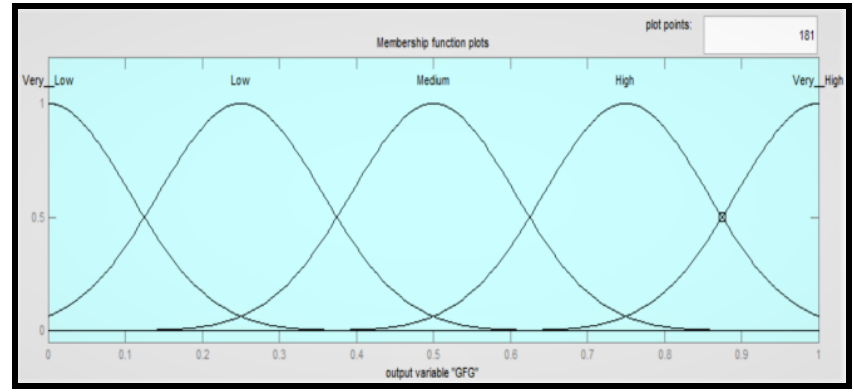

Fig. 9. Membership functions graph of output (GFG)

Table 5. Selected fuzzy rules

\begin{tabular}{|c|c|c|c|}
\hline $\begin{array}{c}\text { Rules } \\
\text { No. }\end{array}$ & $\begin{array}{c}\text { Input-1 } \\
(\text { GRC-Ra })\end{array}$ & $\begin{array}{c}\text { Input-2 } \\
(\text { GRC- } \\
\text { MRR })\end{array}$ & $\begin{array}{c}\text { Output } \\
(\text { GFG })\end{array}$ \\
\hline 1 & Very High & Very High & Very High \\
\hline 2 & Very High & Medium & High \\
\hline 3 & Medium & Medium & Medium \\
\hline 4 & Low & Low & Low \\
\hline 5 & High & High & High \\
\hline 6 & Low & Medium & Low \\
\hline 7 & High & Medium & High \\
\hline 8 & Low & Medium & Medium \\
\hline 9 & Very High & Low & Medium \\
\hline 10 & High & Low & Medium \\
\hline 11 & Medium & Low & Medium \\
\hline
\end{tabular}

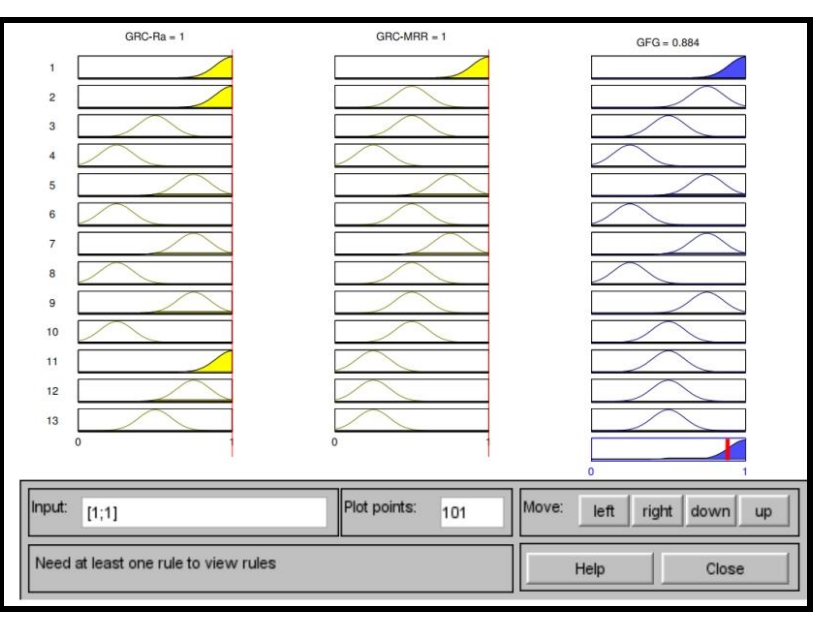

Fig. 10. Rules viewer for highest value of GFG (run 1)

Further, the mean GRG and Mean GFG of each input is estimated with respect to their levels and mentioned in Table 6 and Table 7. Higher mean values for each input denote the corresponding level. Using grey optimization, the optimization setting is found as $\mathrm{t}_{1}-\mathrm{s}_{1}-\mathrm{v}_{1}$ i.e. depth of cut $=0.15 \mathrm{~mm}$, feed $=0.06 \mathrm{~mm} / \mathrm{rev}$ and cutting speed $=60 \mathrm{~m} / \mathrm{min}$ while, using grey-fuzzy, the optimal setting is evaluated as $t_{1}-s_{1}-v_{2}$ i.e. depth of cut $=0.15 \mathrm{~mm}$, feed $=0.06$ $\mathrm{mm} / \mathrm{rev}$ and cutting speed $=120 \mathrm{~m} / \mathrm{min}$. Also, the rank of GRG and GFG is obtained based on the highest value (difference of maximum and minimum value of each input). For both (GRG and GFG), feed exhibited the largest impact (as their rank is 1) trailed by the depth of cut and speed as found in Table 6 and Table 7.

Further, a verification turning experiment was carried using the obtained optimal set of data and the results for grey and grey-fuzzy are mentioned in Table and Table respectively. The grey-fuzzy technique exhibited better results compared to grey relational analysis. Using the grey-fuzzy concept, about $9 \%$ less $R_{a}$ and 2.612 times more MRR is noticed compared to grey relational analysis. However, it can be stated that the grey-fuzzy logic has better capability to estimate optimal conditions compared to grey relational analysis and it is recommended for industrial applications.

Table 6. Estimated mean GRG, optimal settings and test results

\begin{tabular}{|l|l|l|l|l|c|}
\hline \multirow{2}{*}{ Terms } & \multicolumn{4}{|l|}{ Mean GRG } & \\
\cline { 2 - 6 } & Levels & L2 & L3 & L4 & Rank \\
\cline { 2 - 6 } & L1 & 0.603 & 0.549 & 0.524 & 2 \\
\hline $\mathrm{t}$ & $\mathbf{0 . 7 9 2}$ & 0.669 & 0.496 & 0.386 & 1 \\
\hline $\mathrm{s}$ & $\mathbf{0 . 6 5 2}$ & 0.621 & 0.543 & 0.528 & 3 \\
\hline $\mathrm{v}$ & \multicolumn{5}{|l|}{$\mathrm{t}_{1}(0.15 \mathrm{~mm})-\mathrm{s}_{1}(0.06 \mathrm{~mm} / \mathrm{rev})-\mathrm{v}_{1}(80 \mathrm{~m} / \mathrm{min})$} \\
\hline $\begin{array}{l}\text { Optimal } \\
\text { Settings }\end{array}$ & $\begin{array}{l}\text { Results at } \\
\text { optimal run }\end{array}$ & $0.486 \mu \mathrm{m}$ and MRR $=3.3613 \mathrm{~g} / \mathrm{min}$ \\
\hline
\end{tabular}

Table 7. Estimated mean GFG, optimal settings and test results

\begin{tabular}{|l|l|l|l|l|c|}
\hline \multirow{3}{*}{ Terms } & \multicolumn{4}{|l|}{ Mean GFG } & \\
\cline { 2 - 6 } & Levels & L2 & L3 & L4 & Rank \\
\cline { 2 - 6 } & L1 & L2 & 0.556 & 0.531 & 2 \\
\hline $\mathrm{t}$ & $\mathbf{0 . 6 3 6}$ & 0.604 & 0.678 & 1 \\
\hline $\mathrm{s}$ & $\mathbf{0 . 7 4 8}$ & 0.666 & 0.534 & 0.378 & 3 \\
\hline $\mathrm{v}$ & 0.612 & $\mathbf{0 . 6 1 6}$ & 0.558 & 0.541 & 3 \\
\hline $\begin{array}{l}\text { Optimal } \\
\text { Settings }\end{array}$ & \multicolumn{7}{|l}{$\mathrm{t}_{1}(0.15 \mathrm{~mm})-\mathrm{s}_{1}(0.06 \mathrm{~mm} / \mathrm{rev})-\mathrm{v}_{1}(120 \mathrm{~m} / \mathrm{min})$} \\
\hline $\begin{array}{l}\text { Results at } \\
\text { optimal run }\end{array}$ & \multicolumn{7}{|l}{$\mathrm{R}_{\mathrm{a}}=0.442 \mu \mathrm{m}$ and MRR $=8.7800 \mathrm{~g} / \mathrm{min}$} \\
\hline
\end{tabular}

\section{CONCLUSIONS}

Based on the results, hard turning performance under wet cooling conditions is noticed to be better than dry cutting. Also, the current finding definitely attracts the machinist to use PVD coated tool in turning of hard metals up to $240 \mathrm{~m} / \mathrm{min}$ of speed and 0.18 $\mathrm{mm} / \mathrm{rev}$ of feed to achieve higher MRR with considerable finish $\left(\mathrm{R}_{\mathrm{a}}<1.6 \mu \mathrm{m}\right)$. The feed is the topmost impactful factor (97.53\% contribution) towards $R_{a}$ as it severely affects the quality of the finish. Similarly, the depth of cut (43\% contribution) is the topmost influencing term for MRR succeeded by cutting speed $(38.38 \%)$ and feed $18.09 \%$. The 
maximum diameter error (\%) was traced to be below $\pm 0.6 \%$ for entire experiments which confirms the stable machining and can be recommended for precision work. The grey-fuzzy hybrid approach was found to be effective as improved results of $R_{a}$ and MRR were found compared to the grey approach. Finally, wet cooling coupled with PVD tool in hard turning of EN 31 steel at the parametric setting of cutting speed $=120 \mathrm{~m} / \mathrm{min}$, feed $=0.06 \mathrm{~mm} / \mathrm{rev}$, and cutting depth $=0.15 \mathrm{~mm}$ is recommended for industrial application. Future, research plans should be devoted to studying the tool wear, tool vibration, cutting force, and cutting power in the machining of EN 31 steel under wet cooling environment. Also, cryo-machining, nanofluid with MQL can be used to compare the current obtained findings.

\section{REFERENCES}

1. Kumar, R., Sahoo, A. K., Mishra, P.C., Das, R.K., (2018). An investigation to study the wear characteristics and comparative performance of cutting inserts during hard turning, International Journal of Machining and Machinability of Materials, 20(4), pp. 320-344.

2. Shihab, S. K., Khan, Z. A., Mohammad, A., Siddiquee, A. N., (2014). A review of turning of hard steels used in bearing and automotive applications, Production \& Manufacturing Research, 2(1), pp. 2449.

3. Vogli, E., Tillmann, W., Selvadurai-Lassl, U., Fischer, G., Herper, J., (2011). Influence of Ti/TiAlNmultilayer designs on their residual stresses and mechanical properties, Appl. Surf, 257(20), pp. $8550-8557$.

4. Tillmann, W., Sprute, T., Hoffmann, F., Chang, Y.Y., Tsai, C.Y., (2013). Influence of bias voltage on residual stresses and tribological properties of TiAlVN-coatings at elevated temperatures, Surf. \& Coat. Tech, 231, pp. 122-125.

5. Mia, M., Gupta, M.K., Singh, G., Krolczyk, G., Yu, D., (2018). An Approach to Cleaner Production for Machining Hardened Steel Using Different Cooling-Lubrication Conditions, J. Clean. Prod, 187, pp.1069-1081.

6. Vishnu, A. V., Kumar, P. J., Ramana, M. V., (2018). Comparison among Dry, Flooded and MQL Conditions in Machining of EN 353 Steel Alloys-An Experimental Investigation, Materials Today: Proceedings, 5(11), pp. 24954-24962.

7. Mukherjee, S., Kamal, A., Kumar, K., (2014). Optimization of Material Removal Rate during Turning of SAE 1020 Material in CNC Lathe using Taguchi Technique, Procedia Engineering, 97, pp. 29-35.

8. Mia, M., Dey, P. R., Hossain, M. S., Arafat, M. T., Asaduzzaman, M., Ullah, M. S., Zobaer, S. T., (2018). Taguchi S/N based optimization of machining parameters for surface roughness, tool wear and material removal rate in hard turning under $M Q L$ cutting condition, Measurement, 122, pp. 380-391.

9. Powar, P. P., \& Raval, H. K., (2016). A study on process parameters effect in hard turning of EN24 steel using minimum quantity lubrication $(M Q L)$. International Journal of Modern Manufacturing Technologies, 8(2), PP. 66-71.

10. Kumar, R., Sahoo, A.K., Mishra, P.C., Das , R.K., (2018). Comparative study on machinability improvement in hard turning using coated and uncoated carbide inserts: part II modeling, multiresponse optimization, tool life, and economic aspects, Advances in Manufacturing, 6(2), pp. 155-175.

11. Kumar, R., Pandey, A., Panda, A., Mallick, R., Sahoo, A.K., (2021). Grey-Fuzzy Hybrid Optimization and Cascade Neural Network Modelling in Hard Turning of AISI D2 Steel, International journal of integrated engineering, 13(4), pp. 189-207.

12. Pandey, A., Kumar, R., Sahoo, A.K., Paul, A., Panda, A., (2019). Performance Analysis of Trihexyltetradecylphosphonium Chloride Ionic Fluid under MQL Condition in Hard Turning, International journal of automotive and mechanical engineering, 17(1), pp. $7629-7647$.

13. Nikam, B., Khadtare, A., \& Pawade, R., (2021). Machinability Assesment of AISI 4140 Hardened Steel Using CBN Inserts In Hard Turning, International Journal of Modern Manufacturing Technologies, Vol. XIII(No.1), pp. 140-148.

14. Senthilkumar, N., Sudha, J., Muthukumar, V., (2015). A grey-fuzzy approach for optimizing machining parameters and the approach angle in turning AISI 1045 steel, 10(4),pp 195-208.

15. Venkataramaiah, P., DharmaReddy, K., Meramma, P., (2015). Analysis on influence of feed rate and tool geometry on cutting forces in turning using Taguchi method and fuzzy Logic, Procedia Materials Science, 5, pp. 1692-1701.

16. Madival, S., Ahmed, M. R., Halappa, M. L., Marulaiah, L., (2019). Application Potential of Fuzzy and Regression in Optimization of MRR and Surface Roughness during Machining of C45 Steel, Periodica Polytechnica Mechanical Engineering, 63(2), pp. 132-139.

17. Mayer, J. R. R., Phan, A.V., Cloutie, G., (2000). Prediction of diameter errors in bar turning: a computationally effective model, Applied Mathematical Modelling, 24(12), pp. 943-956.

Received: August 5, 2021 / Accepted: December 15, 2021 / Paper available online: December 20, 2021 () International Journal of Modern Manufacturing Technologies 